\title{
Microstructural Investigation of Reinforced Concrete Exposed to Cyclic Wetting and Drying
}

\author{
Wahyuniarsih Sutrisno", Priyo Suprobo ${ }^{\#}$, Endah Wahyuni", Data Iranata ${ }^{\#}$ \\ \#Department of Civil Engineering, Institut Teknologi Sepuluh Nopember Surabaya 60111 Indonesia \\ E-mail:niar1206@gmail.com,priyo@ce.its.ac.id, endah@ce.its.ac.id,iranata80@gmail.com
}

\begin{abstract}
Concrete which placed in an aggressive environment has a great chance to suffer from damage especially for concrete put in the marine environment. In this situation, damage process in concrete is mainly caused by chloride ingress. The chloride penetrates into the concrete by various mechanisms. For concrete submerged in seawater, the chloride solution penetrates into the concrete trough diffusion mechanism and cause damage over the time. However, in real life, reinforced concrete structure mostly placed in the partially saturated area and subjected to the repeated actions of the wetting and drying cycle. This condition makes the concrete structures more vulnerable to corrosion than structures in a fully saturated condition. Therefore, this study investigates the changes in concrete microstructures condition due to repeated actions of wetting and drying. The samples were exposed by $5 \% \mathrm{NaCl}$ solution through the different configuration of wet and dry duration. The microstructural condition was observed by several methods such as XRF, SEM and EDX analysis. Major constituent phases of concrete and the differences in their distribution due to different duration of wet and dry were observed in this study. Finally, from the investigation, it was found that there were noticeable differences in chloride and magnesium percentage in the samples. This result acts as evidence that the duration of wet and dry can affect the formation of particular compounds such as chloroaluminate, quartz, brucite, and dolomite in the samples which plays roles in the damage process of concrete.
\end{abstract}

Keywords - reinforced concrete; microstructural; cyclic wetting; drying

\section{INTRODUCTION}

Chloride-induced corrosion is the great durability issue in a reinforced concrete structure for years [1]-[3]. In marine area, chloride ions present in the sea water and marine breeze. Due to concrete microstructure condition, which contains many pores, the chloride ion, water, and oxygen manage to reach concrete-steel interface and start to initiate the corrosion process [4]-[6]. As time passed, the volume of corrosion product will increase and eventually caused cracking in the concrete. The cracking will propagate within the concrete cover and cause a crack at the concrete surface. This crack will lead concrete to higher risk for corrosion development and for a long time it will finally cause strength degradation in the concrete structures [7], [8].

Several studies related to corrosion had been conducted by previous researchers. The majority of the studies assumed that the concrete is in the fully saturated condition with diffusion as a key mechanism of chloride penetration [9], [10]. The previous experimental method frequently used the impressed current method. This method also is widely known as a galvanostatic method. The purpose of this method is to investigate the corrosion process and cracking due to corrosion [11]-[15]. This method applied by inducing the corrosion through impressed current and submerging the concrete specimen into the $\mathrm{NaCl}$ solution. However, this method cannot represent the actual condition which concrete is mainly placed in the splash zone and subjected to wetting and drying cycle.

The method of chloride transport in concrete are different based on the environmental condition. In fully saturated condition, chloride transport mechanism mainly occurs by diffusion. However, in the splash zone or tidal zone, which concrete is in partially saturated condition, the chloride transport mechanism does occur by not only diffusion but also a combination of several mechanisms such as absorption and convection [16]. Cyclic wetting and drying lead to continuous fluid and moisture movement through concrete pores. As a result, the microstructural condition of concrete is continuous to change and makes concrete with this type of exposure is more vulnerable than concrete placed fully submerged area. The process of chloride transport during cyclic wetting and drying shows in Fig. 1.

When chloride ion penetrates into the concrete, the structure of calcium chloroaluminate formed. This compound will affect the microstructural condition of the concrete. As widely known, concrete quality is affected by its microstructural condition. As a homogenous material, which consists of aggregate, cement, water and other agents, 
concrete quality and strength could not be separated from its microstructural condition. Furthermore, the homogeneity of concrete can make concrete with same design category have different quality depend on its mixing technique and quality of the constituent material. Therefore, the microstructural condition is critical as a representative of the overall performance of the concrete especially for concrete exposed to the marine environment.

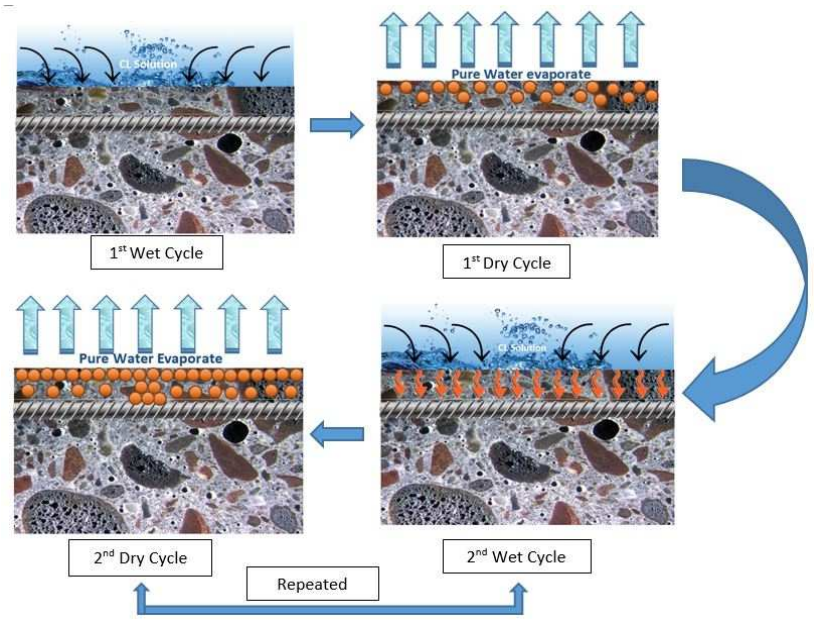

Fig. 1 Chloride transport illustration under wet and dry cycle [16]

Several researchers have been conducted studies related to the microstructural condition of the concrete. Karthikeyan et al. conducting an experimental test to investigate the microstructural condition of concrete which concrete cured in seawater or normal water [17]. This study also investigated the microstructural differences of concrete which cured in normal water and exposed subsequently to seawater. This study has shown that the microstructural condition of concrete is changed due to different curing media and exposure. In 2011, Sosa et al. also performed an investigation of concrete microstructures depend on its exposure condition which is natural atmospheric, permanent immersion and alternating cycles [18]. It also is shown that there were differences in the microstructural condition of concrete due to the exposure condition. The study related to the microstructure of concrete for long time exposure also has been performed by Jacobsen in 2013. The study showed that there was a different distribution of the major constituent phase of concrete after two years exposure.

Even though many studies related to the microstructural condition of concrete exposed to seawater has been performed, but the effect of the influence of the ratio of wetdry durations has not been thoroughly investigated. According to research by Sutrisno et al. in 2016, the chloride profile of the concrete subjected to wetting and drying cycle is greatly affected by wetting and drying period [19]. Therefore, this paper is focused on investigating the microstructural condition of the concrete due to three different wet and dry duration ratio. The analysis of contours of concrete is performed by using scanning electron microscopy (SEM) coupled to elemental analysis (EDS) and $\mathrm{X}$-Ray Fluorescent (XRF).

\section{MATERIAL AND METHOD}

The samples used in this research is concrete cubes with dimension $150 \times 150 \times 150 \mathrm{~mm}$. Also, a steel reinforcement was embedded in the concrete with distance $40 \mathrm{~mm}$ from the exposed surface. The steel reinforcement has $19 \mathrm{~mm}$ dimension with deformed geometry. The concrete used for the sample is normal concrete made from Portland Pozzoland Cement (PPC) and local aggregates with 0.5 water per cement ratio (w/c).

Before the mixing process, the aggregates were washed and placed in the storage bucket for one day with several small holes in the bottom part to allow the excess water drain. At the next day, the aggregate was dried until reach saturated surface dry (SSD) condition. The cubes molds were prepared with a special configuration to allow single reinforcement to embed in the concrete.

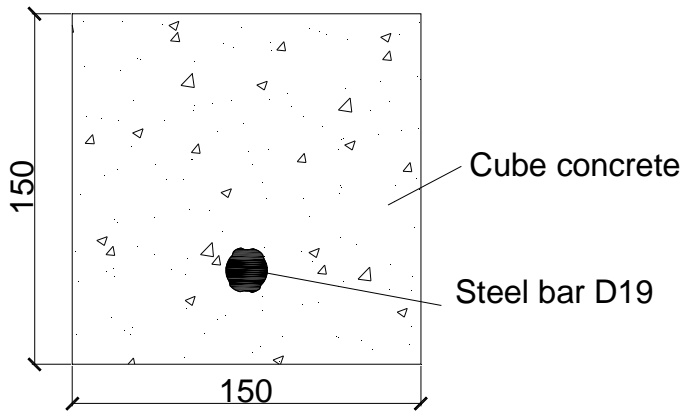

Fig. 1 Cross section of the model

\section{A. Exposure History}

The samples were exposed to $5 \% \mathrm{NaCl}$ solution to simulate the sea water. Three variations of wet and dry duration used in this experiment. The first variation used wet per dry duration ratio $<0.5$. This condition achieved by exposing the sample with 1-hour wetting and 7 hours drying. The second variation used wet per dry duration ratio $>0.5$. This condition obtained by exposing the sample with 3 hours wetting and 5 hours drying. The last variation is for wet per dry duration ratio $>1$. This variation can be categorized into fully submerged because the wetting time is more than 1 . Therefore, this configuration achieved by submerging the samples into $\mathrm{NaCl}$ solution.

The samples were placed in the three different chambers with the same environmental condition, including temperature and humidity to simulate the wetting and drying cycle. However, the time for wet and dry duration was different for all three chambers. The $5 \% \mathrm{NaCl}$ solution was sprayed from a nozzle which connected to the pipe. Furthermore, the water pump was also attached to the timer switch which manages the spraying time. The drying cycle was performed by exposing the samples with an infrared lamp to achieve a temperature of $30^{\circ} \mathrm{C}$. A thermostat was connected to the lamp to adjust the temperature in the chamber. When the temperature reaches over $30^{\circ} \mathrm{C}$, the thermostat will cut the electricity which makes the lamp off vice versa. 


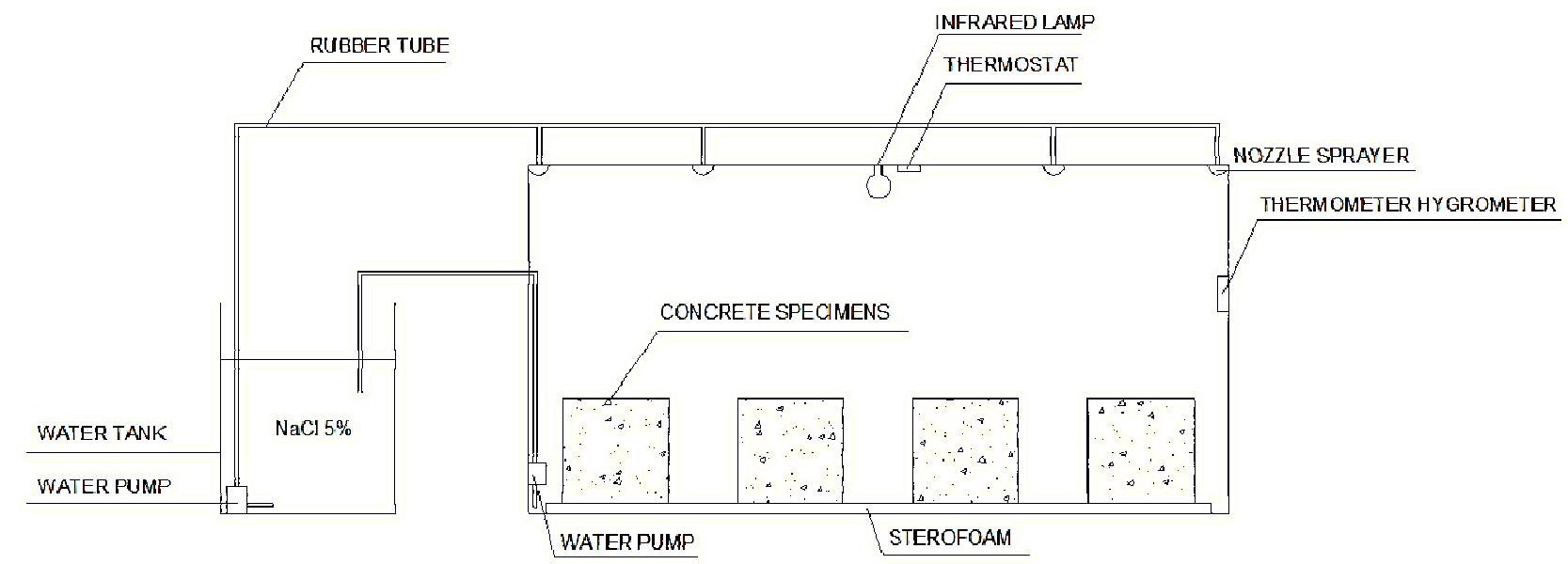

Fig. 3 Experimental setup of cyclic wetting and drying

\section{B. Microstructural Investigation}

The microstructural investigation was performed by Scanning Electron Microscope coupled with EDX and also $\mathrm{X}$-ray Fluorescence (XRF). The samples, which will be tested, were taken from the chamber and stored in the room temperature for 24 hours to stabilize the samples and drain the excess water.

The XRF test was performed by Rigaku ZSX Primus II machine. The sample used in this test had $2.5 \times 2.5 \times 1 \mathrm{~mm}$ and was obtained by sliced the concrete sample at the appropriate location. The XRF test was performed to acquire data related to the elemental composition of the sample after exposed to cyclic wetting and drying cycle. The samples were mounted on the mounting block and placed at the center of the stage. The sample will be vacuumed at the XRF machine, and after this step had finished, the elemental composition analysis was started.

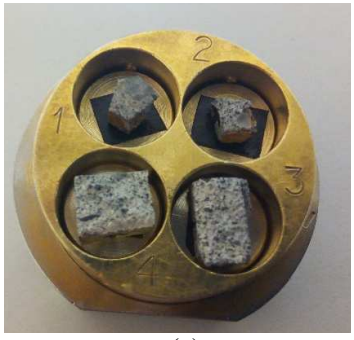

(a)

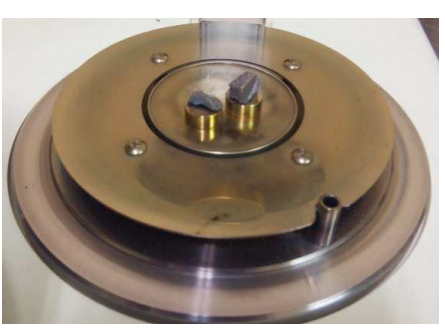

(b)
Fig. 4 Concrete samples before (a) and after (b) coating

To obtained data regarding the microstructure of the sample. The SEM/EDX test performed according to ASTM C 1723. The samples, which have been exposed to a different configuration of wetting and drying, were cut into small pieces, with size approximately $5 \times 5 \times 5 \mathrm{~mm}$, at the appropriate location. Prior to the test, the sample was vacuumed and coated with gold to obtain more conducting surface. In addition, this process will make the output image of SEM clearer. The SEM test was performed simultaneously with EDX test using JSM 7600F Field Emission Scanning Electron Microscope machine. The machine used energy-dispersive analyzer for x-rays at an operating voltage of $15 \mathrm{keV}$ to analyze the samples.
Backscattered electron, Secondary electron, and x-ray images were obtained from the test in the appropriate area.

\section{Chloride Content Investigation}

There are two methods to determine the chloride content in the concrete which are the total chloride content method and free chloride content method. The determination by free chloride content method is rather easy in solutions but becomes more complicated when dealing with hardened concrete. Therefore, for this research, the total chloride content method was used. For total chloride content method, the sample was taken from hardened concrete. The concrete cube was sliced in every certain thickness, crushed and powdered. The powdered concrete then subsequently analyzed to obtain the chloride profile.

The chloride is analyzed by titration. Before the titration process, Samples were chilled in a desiccator on the day of analysis. For each layer, the samples were crushed and shieves. Two grams of powdered sample was taken and digested with nitric acid.

Before titration, the sample was stored at room temperature. The total chloride content of the sample was analyzed by using an argentometric titration, with an $\mathrm{AgNO}_{3}$ solution and a silver billet electrode. The chloride concentration was calculated from the modulation point of a plot of the potential versus titrant volume. The titrant was dispensed by an automatic titrator.

\section{RESULT AND DISCUSSION}

After five months' exposure under fully submerged and wet-dry configuration, the sample was removed from the chambers. All samples stored at the room temperature for 24 hours to stabilize the moisture condition and drain the excess water.

\section{A. Visual Observation}

The visual inspection of the samples was conducted one day prior to the microstructural testing date. Based on the observation, as presented in Fig. 5, there are distinct differences in the roughness of each sample. Sample with wet and dry configuration has a rougher surface than the sample with fully submerged configuration.

Furthermore, the sample with fully submerged configuration shows thin layer on the surface. For structures 
exposed to the marine environment, especially for structures in fully submerged condition, the formation of a thin layer of aragonite and brucite in the concrete surface is very common. The compounds act as a protective layer at the concrete surface. This layer can reduce the chloride penetration and decrease the amount of chloride in the pore surface. Therefore, the visual of the concrete surface with fully submerged configuration is smoother compared with the sample with wet and dry configuration.

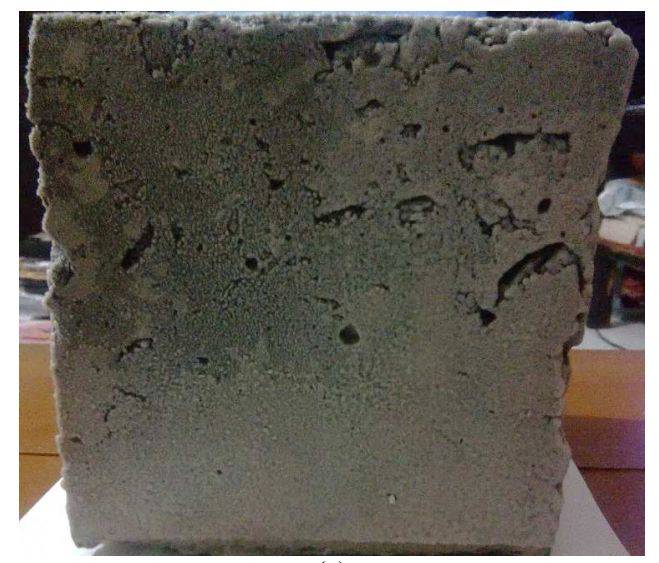

(a)

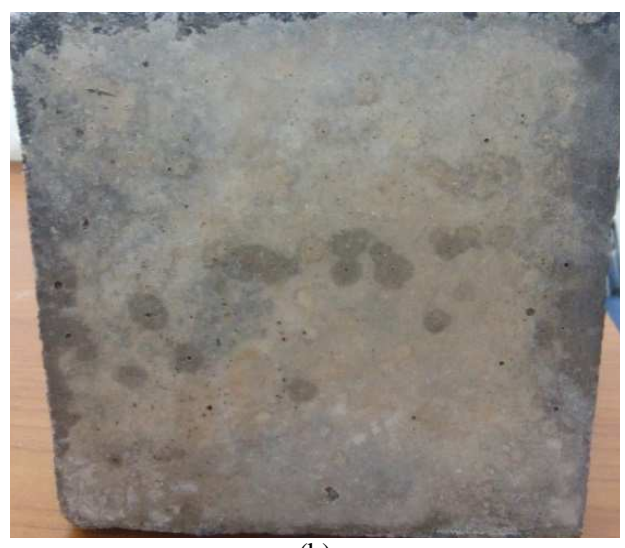

(b)

Fig. 5 Comparison of the concrete surface condition under wetting and drying configuration and fully submerged condition after five months exposure

\section{B. Investigation of Chloride Profile}

The chloride profile analysis performed by argentometric titration. Fig. 6 shows the result of the chloride profile analysis of the sample at the fifth-month exposure. Based on Fig. 6, the chloride concentration with 3 hours wet duration has highest chloride concentration because this configuration combines more than one transport mechanism which is diffusion and convection.

At the beginning of exposure duration, diffusion is the main mechanism. Therefore, the chloride concentration for fully submerged specimens had the highest concentration. At time passed, the convection starts to show its effect. The chloride concentration at five months' exposure shows that the chloride concentration of the concrete with 3 hours wetting and 5 hours drying condition keep increased and passed the fully submerged samples. However, concrete with one-hour exposure condition still has the lowest chloride concentration from the beginning until the end of exposure duration. This condition happened because the sample has a very short wetting period so, the diffusion mechanism does not occur perfectly. It also can be noticed that due to very long drying period, the main mechanism of this configuration is convection which makes the transport period of chloride become longer.

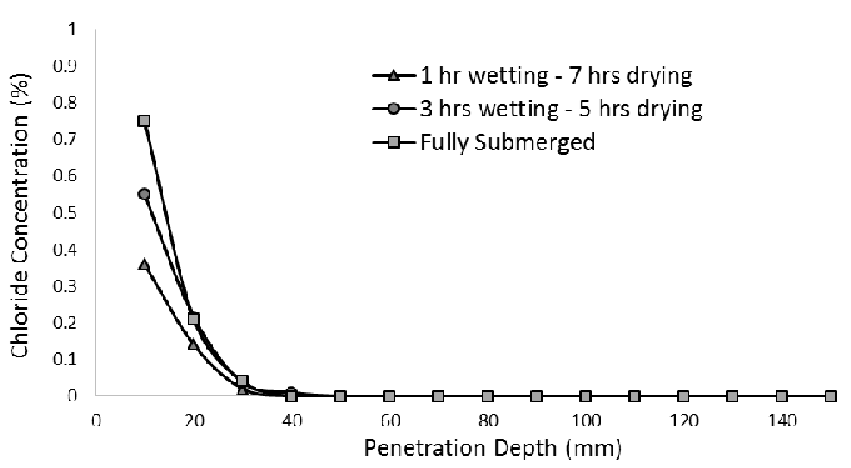

(a)

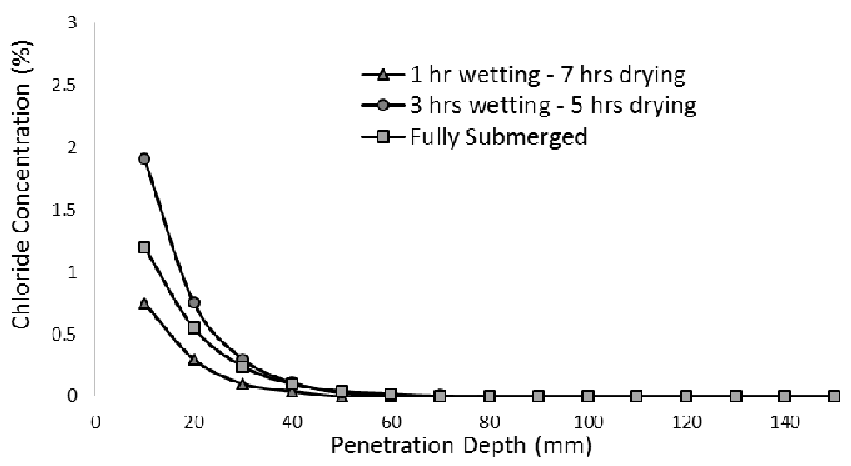

(b)

Fig. 6 Chloride penetration at first-month exposure (a) and fifth-month of exposure (b)

\section{Investigation of Internal Structures}

The investigation of internal structures was performed by two techniques, which are SEM/EDX and XRF. The samples for the test was taken from the inner location of concrete cubes. Fig. 7 shows the internal structures of three samples. The secondary electron image was taken by SEM technique with a magnification of $2000 \mathrm{X}$ until $3000 \mathrm{X}$ and operating voltage of $15 \mathrm{kV}$.

The same image with larger magnification shows in Fig. 8. In that figure, cement constituent phases of $\mathrm{C}-\mathrm{S}-\mathrm{H}$, which attached with chloroaluminates is presented. The figure showed the clear shape of ettriggite and filled up the concrete pores.

Due to exposure to $\mathrm{NaCl}$ solution, the chloride slowly enters into the concrete as contamination. The element will react with $\mathrm{C}_{2} \mathrm{~A}$ or $\mathrm{C}_{4} \mathrm{AH}_{13}$ to form complex Calcium Chloroaluminates Hydrates (e.g., $3 \mathrm{CaO} . \mathrm{Al}_{2} \mathrm{O}_{3} \cdot \mathrm{CaCl}_{2} \cdot 10$ $\mathrm{H}_{2} \mathrm{O}$ ) or also known as Friedel's salt. The calcium chloroaluminates has a needle shape crystal and normally will be attached to calcium silicate hydrates. Based on Fig. 7, it can be seen that sample with three hours wet and five hours dry has the largest amount of chloroaluminates. The image shows that the chloroaluminates are presented almost in every pore of the concrete. However, concrete with fully 
submerged and one hour wet-seven hours' dry configuration show only little chloroaluminates at each pore.

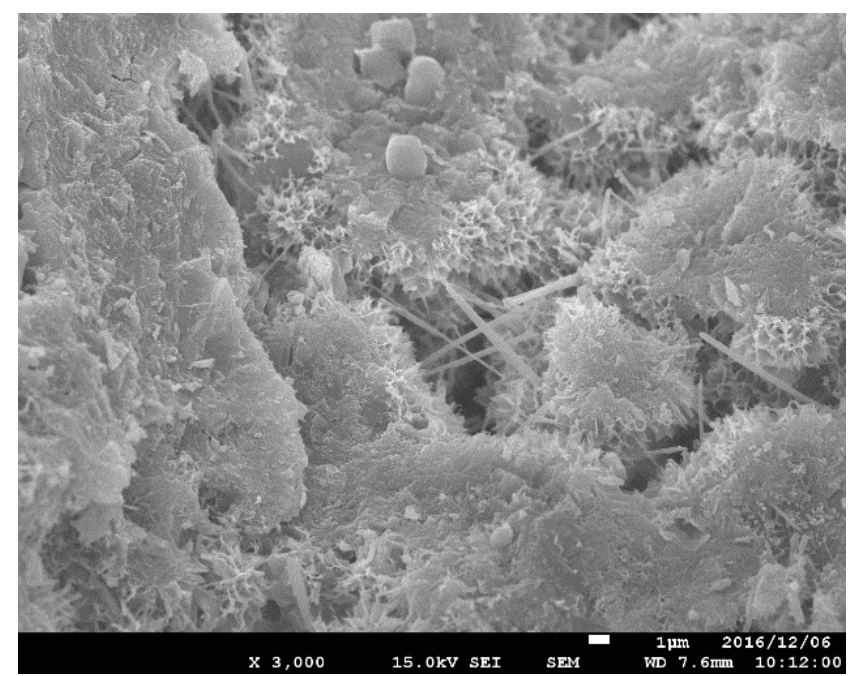

(a)

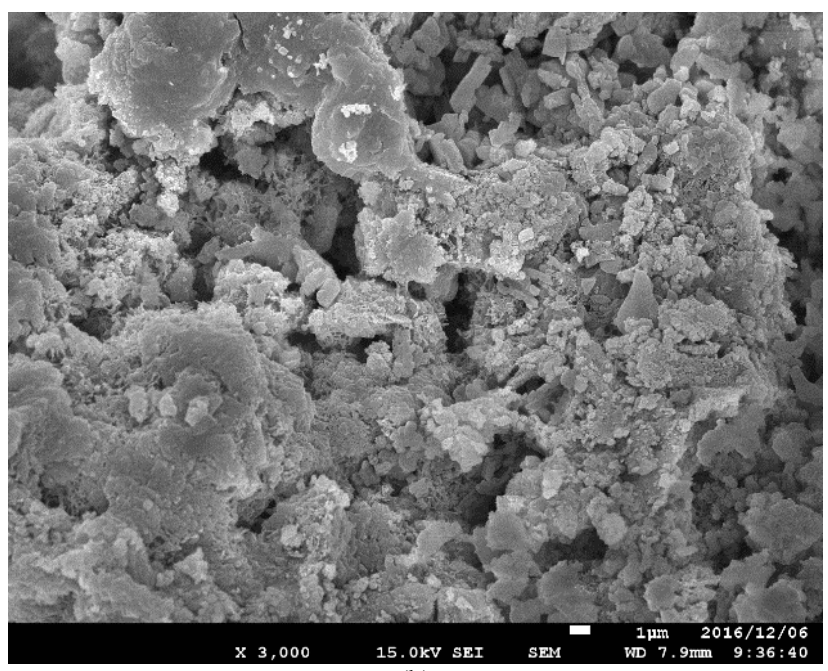

(b)

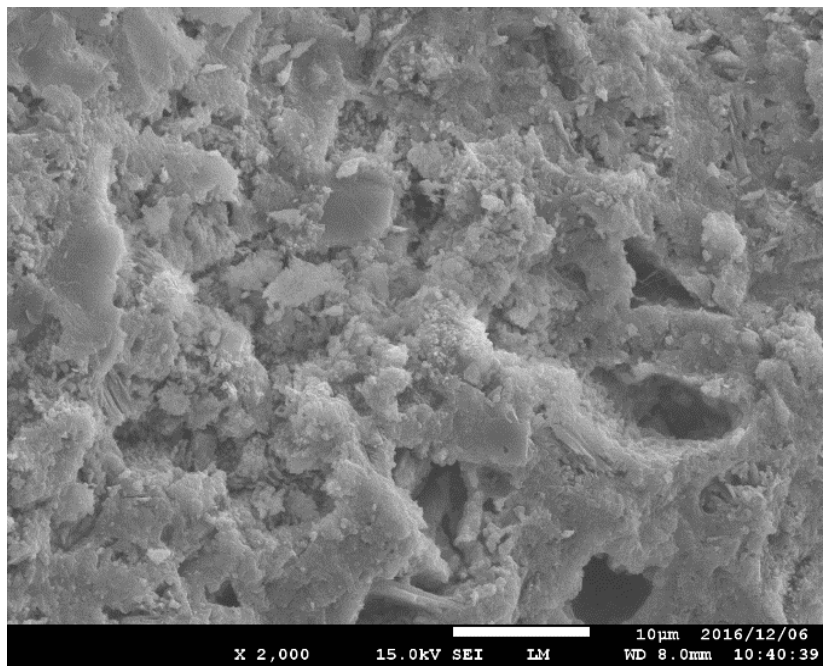

Fig. 7 Comparison of internal structure for the sample with (a) 3 hours wet and 5 hours dry configuration (b) 1 hour wet and 7 hours dry configuration (c) fully submerged configuration
The EDS spectra were taken from specific regions of the sample, as shown in Fig. 9, and it indicated the presence of $\mathrm{Si}, \mathrm{Ca}, \mathrm{Mg}, \mathrm{Al}$, and $\mathrm{Cl}$ in the sample. The percentage of each element also obtained from the XRF analysis. Even though the SEM/EDS and XRF technique is not completely appropriate for the accurate estimation of the chloride concentration from bulk regions, it has been used as a first approximation to arrive at a qualitative identification of the microchemistry. Table 1 shows that concrete with 3 hours wetting and 5 hours drying has highest chloride content compared to the other samples. This condition indicates that this sample is more vulnerable to corrosion due to the rapid increase of chloride concentration.

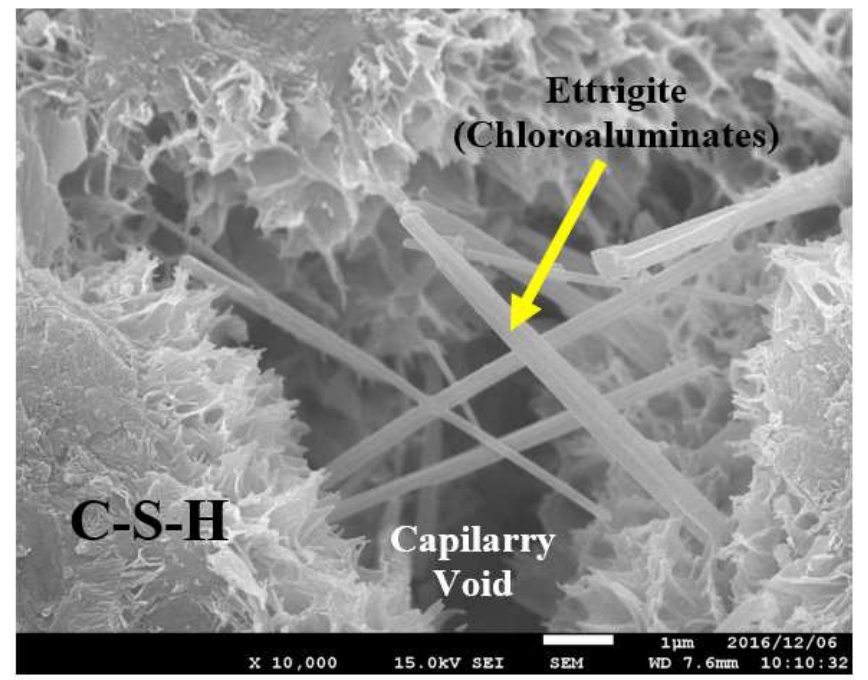

Fig. 8 Magnified view of samples with 3 hours wet and 5 hours dry configuration which showing the various constituents in hydrated cement paste

Based on Table 1 it can be seen that all samples have a different percentage of the element. The profile of Si content in the sample showed the effect of the penetration depth of the sample. The presence of $\mathrm{Si}$ in the sample can indicate the present of Quartz $\left(\mathrm{SiO}_{2}\right)$. Quartz is one of the main components which responsible for mechanical resistance of concrete. If the environment aggressiveness increases, a higher loss of quartz could occur on the surface. Sample with 3 hours wetting and 5 hours drying duration has lowest $\mathrm{Si}$ content. It is indicating that the amount of $\mathrm{Si}$ is decreases due to the influence of external environmental condition. The sample with 1 hour wetting and 7 hours drying condition has the lowest amount of $\mathrm{Si}$ because of least wetting time which results in the slower penetration of aggressive agent.

The presence of $\mathrm{Mg}$ is also indicating the existence of Dolomite $\left(\mathrm{CaMg}\left(\mathrm{Co}_{3}\right)_{2}\right)$ and Brucite $\left(\mathrm{Mg}(\mathrm{OH})_{2}\right)$. Dolomite and Brucite. Sample with wetting and drying configuration shows the higher value of $\mathrm{Mg}$ compared with the fully submerged condition. This condition occurs because drying time in wetting and drying configuration causing the formation of a calcareous layer in the concrete surface. This crystal layer acts as a barrier on the concrete surface and plays an important role to slow down the transport process of chloride ions inside the sample. However, if the wetting time is sufficient, this layer can be dissolved in the water, and the 
ion can infiltrate into the concrete and cause damage to concrete pores where the drying time occurs.

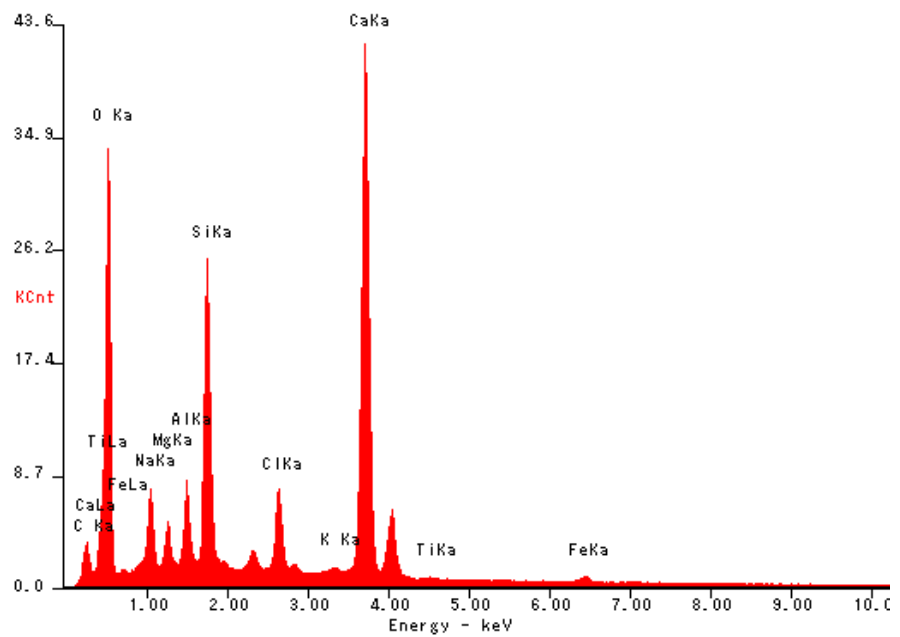

(a)

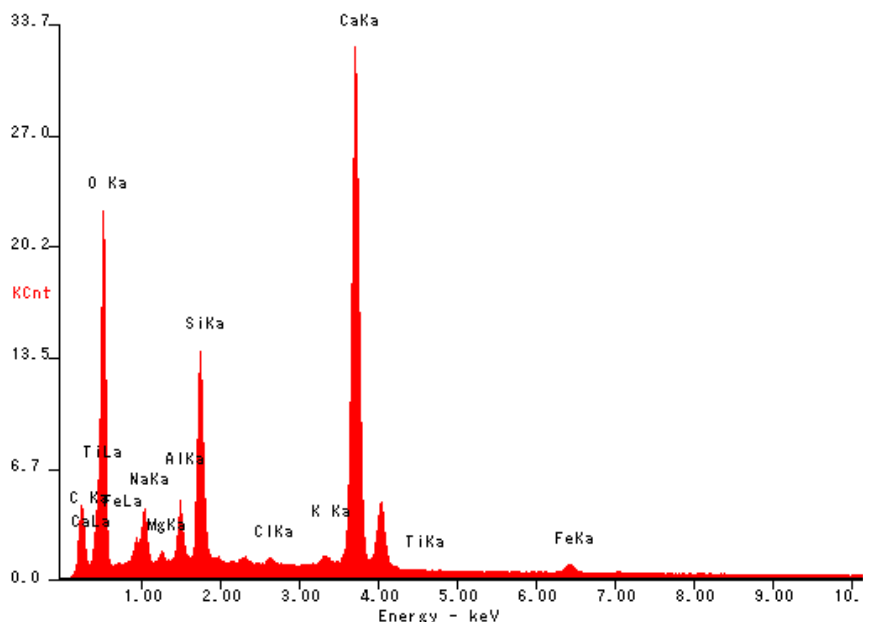

(b)

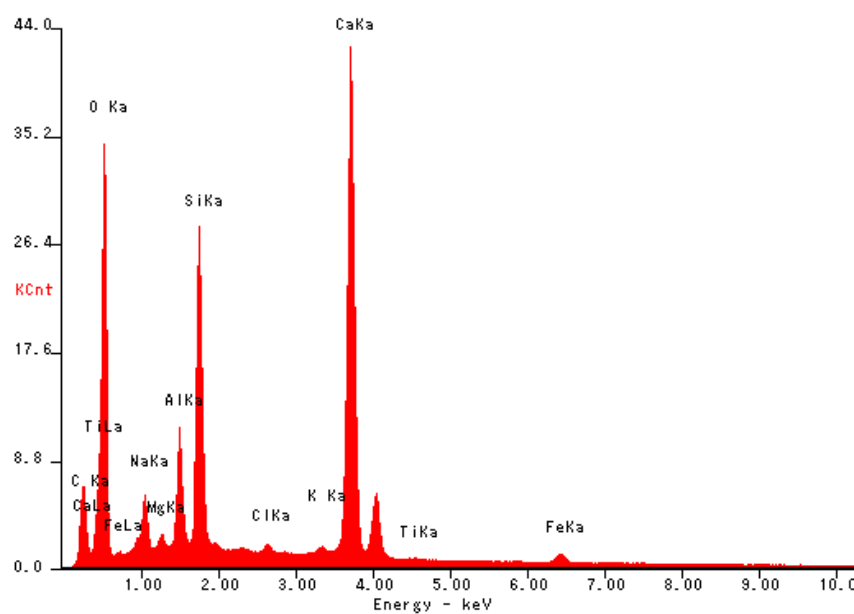

(c)

Fig. 9 EDS spectra for the sample with (a) 3 hours wet and 5 hours dry configuration (b) 1 hour wet and 7 hours dry configuration (c) fully submerged configuration

\section{CONCLUSIONS}

An experimental test was conducted for five months to observe the effect of wetting and drying configuration to concrete internal structures. After five months exposure with a different type of exposure configuration, the internal structures show significant differences. The concrete with 3 hours wetting and 5 hours drying configuration has worst internal structures and surface condition during past five months. Due to a different configuration of wetting and drying duration, the sample with this kind of exposure shows the lowest chloride content and higher silica content. This condition because this sample has the lowest wetting time, so the diffusion process cannot occur perfectly. Finally, it can be concluded that different configuration of wetting and drying duration can affect the whole internal structures of concrete which can lead to different type of damage time to concrete.

\section{ACKNOWLEDGMENT}

All of the authors acknowledge the financial support from Directorate General of Resources for Science, Technology and Higher Education, Ministry of Research, Technology and Higher Education, Republic of Indonesia.

\section{REFERENCES}

[1] S. I. Hong and K. Y. Ann, "Estimation of Corrosion-Free Life for Concrete Containing Ground Granulated Blast-Furnace Slag under a Chloride-Bearing Environment," 2017.

[2] M. U. Khan, S. Ahmad, and H. J. Al-gahtani, "Chloride-Induced Corrosion of Steel in Concrete: An Overview on Chloride Diffusion and Prediction of Corrosion Initiation Time,"Advances in Material Science and Engineering, vol 2017, 2017.

[3] J. Kim, W. J. Mccarter, B. Suryanto, S. Nanukuttan, P. A. M. Basheer, and T. M. Chrisp, "Chloride ingress into marine exposed concrete : A comparison of empirical- and physically- based models," Cem. Concr. Compos., vol. 72, pp. 133-145, 2016.

[4] P. O. Iqbal, "Chloride Transport Coupled with Moisture Migration in Non Saturated Concrete Exposed to Marine Environmet and Application to Cracked Concrete," thesis, University of Tokyo, 2008.

[5] Y. Wang, Q. Li, D. Ph, and C. Lin, "Chloride Diffusion Analysis of Concrete Members Considering Depth-Dependent Diffusion Coefficients and Effect of Reinforcement Presence,"ASCE J. Mater. Civ. Eng. vol. 04015183, no. 9, pp. 1-9, 2016.

[6] Q. Yuan, C. Shi, G. De Schutter, D. Deng, and F. He, "Numerical Model for Chloride Penetration into Saturated Concrete," March, pp. 305-311, 2011.

[7] M. L. T, B. Šavija, G. Ye, E. Schlangen, and K. Van Breugel, "Failure Modes in Concrete Repair Systems due to Ongoing Corrosion," Advances in Material Science and Engineering, vol 2017, 2017.

[8] W. Li, W. Liu, and S. Wang, "The Effect of Crack Width on Chloride-Induced Corrosion of Steel in Concrete," ASCE J. Mater. Civ. Eng., 2017.

[9] W. L. Jin, Y. D. Yan, and H. L. Wang, "Chloride diffusion in the cracked concrete," Conference in Fracture Mechanics of Concrete and Concrete Structures-Assessment, Durability, Monitoring and Retrofitting, pp. 880-886, 2010.

[10] B. Stitmannaithum, H. Q. Vu, and M. Van Tran, "Chloride Penetration into Reinforced Concrete Structure," in Third International Conference on Sustainable Construction Materials and Technologies, 2013.

[11] Y. Yuan, Y. Ji, and S. P. Shah, "Comparison of Two Accelerated Corrosion Techniques for Concrete Structures," ACI Structural Journal, no. 104, pp. 3-6, 2008.

[12] K. Vu, M. G. Stewart, and J. Mullard, "Corrosion-Induced Cracking: Experimental Data and Predictive Models," ACI Structural Journal no. 102, pp. 719-726, 2006.

[13] W. Sutrisno, I. ketut Hartana, P. Suprobo, E. Wahyuni, and D. Iranata, "The Experimental Test of Corrosion Induced Cracking in 
Reinforced Concrete Using Accelerated Method," Proc. 2nd Makassar Int. Conf. Civ. Eng., 2015.

[14] W. Sutrisno, P. Suprobo, E. Wahyuni, and D. Iranata, "Cracking Process of Reinforced Concrete Induced by Non-Uniform Reinforcement Corrosion," Jurnal Teknologi (Sciences \& Engineering), 79:3, 1-6, 2017.

[15] W. Sutrisno, P. Suprobo, E. Wahyuni, and D. Iranata "Analysis of Corrosion Induced Crack in Reinforced Concrete with Smeared Crack Approach," International Journal of Applied Engineering Research, vol 11, No 1, pp. 9970-9974, 2016.

[16] K. Hong, "Cyclic Wetting and Drying and its Effects on Chloride Ingress in Concrete," thesis, University of Toronto, 1998.

[17] T. Karthikeyan, A. Dasgupta, P. Magudapathy, S. Saroja, M. Vijayalakshmi, K. G. M. Nair, K. P. N. Murthy, and B. Raj,
"Microstructure , Microchemistry , and Prediction of Long-Term Diffusion Behavior of Chloride in Concrete," Journal of Materials Engineering and Performance, vol. 15, no. October, pp. 581-590, 2006

[18] M. Sosa, T. P. López, J. Reyes, F. Corvo, P. Quintana, and D. Aguilar, "Influence of the Marine Environment on Reinforced Concrete Degradation Depending on Exposure Conditions," Int. J. Electrochem. Sci., vol. 6, pp. 6300-6318, 2011.

[19] W. Sutrisno, P. Suprobo, E. Wahyuni, and D. Iranata, "Experimental Test of Chloride Penetration in Reinforced Concrete Subjected to Wetting and Drying Cycle," Appl. Mech. Mater., vol. 851, pp. 846$851,2016$. 